\title{
Groundwater Quality in the Borrego Valley, Central Desert, and Low-Use Basins of the Mojave and Sonoran Deserts, California
}

Groundwater provides more than 40 percent of California's drinking water. To protect this vital resource, the State of California created the Groundwater Ambient Monitoring and Assessment (GAMA) Program. The Priority Basin Project of the GAMA Program provides a comprehensive assessment of the State's untreated groundwater quality and increases public access to groundwater-quality information. Selected groundwater basins in the Borrego Valley, Central Desert, and Low-Use Basins of the Mojave and Sonoran Deserts constitute one of the study units being evaluated.

\section{The Borrego Valley, Central Desert, and Low-Use Basins of the Mojave and Sonoran Deserts Study Unit}

The Mojave and Sonoran Deserts include 57 groundwater basins (California Department of Water Resources, 2003). Basins in the Antelope, Mojave River, Coachella, and Colorado River Valleys were discussed by Dawson and Belitz (2012). The remaining 47 basins compose the Borrego Valley, Central Desert, and Low-Use Basins of the Mojave and Sonoran Deserts study unit (CLUB study unit) and were grouped into three study areas. Basins containing few or no public-supply wells are defined as low-use basins. Publicsupply wells are sparse in the 12,103-square-mile area of the CLUB study unit, and this study focused on the 963-square-mile area that is within about 2 miles of a public-supply well.

The climate in the Mojave Desert is characterized as arid high desert, with hot, dry summers and cool

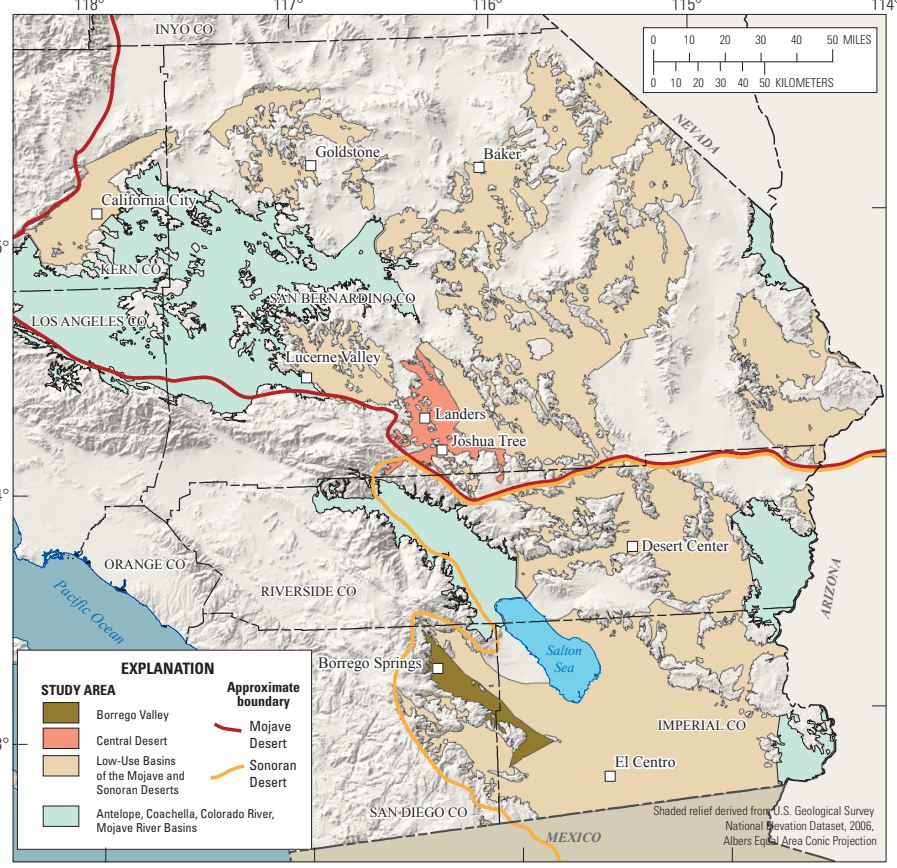
winters with limited rainfall The Sonoran Desert has an arid subtropical climate characterized by long, hot summers, mild winters, and summer and winter rainy seasons. Annual precipitation generally ranges from 0 to 10 inches. Several creeks, washes, and ephemeral streams drain the study unit, flowing into lakes and sinks.

This study evaluated water quality in the part of the aquifer system used for public supply, the primary aquifer system. The primary aquifer system is defined as those parts of the aquifer corresponding to the perforated intervals of wells listed in the California Department of Public Health (CDPH) database. Public-supply wells in the study unit typically are drilled to depths between 350 and 600 feet, consist of solid casing from the land surface to a depth of about 200 to 400 feet, and are perforated below the solid casing. Water quality in the shallower and deeper parts of the aquifer system can differ from that in the primary aquifer system. The primary aquifer system consists of unconfined and confined Pleistocene- to Holocene-age Quaternary alluvium, and to a lesser extent, Tertiary alluvium and sedimentary deposits.

Land use in the CLUB study unit is approximately 91 percent (\%) natural, 6\% urban, and 3\% agricultural. Natural lands are mostly shrubland and bare rock or sediment, with a small percentage of grassland and forest.

Sources of groundwater recharge include runoff from mountains surrounding the basins and infiltration of imported surface water and groundwater used for irrigation. The primary sources of groundwater discharge are water pumped for irrigation and for public supply, natural discharge to streams, and evapotranspiration.

\section{Overview of Water Quality}

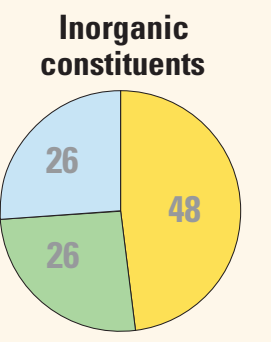

\author{
Organic \\ constituents
}

High $\bigcirc$ Moderate $\bigcirc$ Low or not detected

Values are a percentage of the area of the primary aquifer system with concentrations in the three specified categories. Values on pie chart may not equal $\mathbf{1 0 0}$ due to rounding of percentages.

GAMA's Priority Basin Project evaluates the quality of untreated groundwater relative to human-health and aestheticbased benchmarks established for drinkingwater quality. Benchmarks and definitions of high, moderate, and low concentrations are discussed in the inset box on page 3 .

Inorganic constituents in groundwater commonly are derived from natural sources and processes but also can be affected by human activities. In the CLUB study unit, one or more inorganic constituents were present at high concentrations in about $48 \%$ of the primary aquifer system and at moderate concentrations in about $26 \%$.

Human-made organic constituents can be found in products used in the home, business, industry, and agriculture, and can enter the environment through normal usage, spills, or improper disposal. In this study unit, organic constituents were not present at high concentrations in the primary aquifer system, and one or more organic constituents were present at moderate concentrations in about $5 \%$. 


\section{RESULTS: Groundwater Quality in the Borrego Valley, Central Desert, and Low-Use Basins of the Mojave and Sonoran Deserts Study Unit}

\section{INORGANIC CONSTITUENTS}
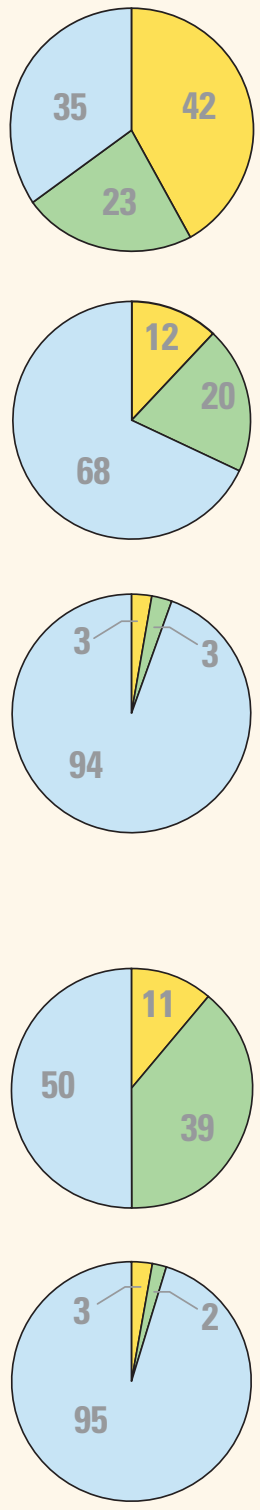

Trace and minor elements

\section{Uranium and radioactive constituents}

\section{Nutrients}

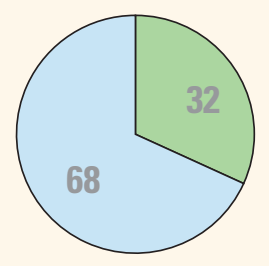

\section{Perchlorate}

\section{Inorganic Constituents with Health-Based Benchmarks}

Trace and minor elements are naturally present in the minerals in rocks and soils, and in the water that comes into contact with those materials. In the CLUB study unit, trace and minor elements were detected at high concentrations in about $42 \%$ of the primary aquifer system, and at moderate concentrations in about $23 \%$ of the system. Fluoride, arsenic, molybdenum, boron, and vanadium were the elements that most frequently occurred at high and moderate concentrations. Chromium also was detected at high concentrations, but in less than $1 \%$ of the primary aquifer system.

Radioactivity is the release of energy or energetic particles during spontaneous decay of unstable atoms. Most of the radioactivity in groundwater comes from the decay of naturally occurring isotopes of uranium and thorium in minerals in the sediments of the aquifer. Uranium and (or) gross alpha radioactivity occurred at high levels in $12 \%$ of the primary aquifer system and at moderate levels in about $20 \%$ of the system.

Nutrients, such as nitrate and nitrite, are naturally present at low concentrations in groundwater. Elevated concentrations generally occur as a result of human activities, such as applying commercial fertilizer or animal waste to land used for crops. Livestock, when in concentrated numbers, and septic systems also produce nitrogenous waste that can leach into groundwater. Nitrate was present at high concentrations in about $3 \%$ of the primary aquifer system and at moderate concentrations in about $3 \%$.

\section{Inorganic Constituents with Non-Health Benchmarks}

(Not included in water-quality overview charts shown on the front page)

Some constituents affect the aesthetic properties of water, such as taste, color, and odor, or may create nuisance problems, such as staining and scaling. The State of California has a recommended and an upper limit for total dissolved solids (TDS) in drinking water. Groundwater naturally contains TDS as a result of the weathering and dissolution of minerals in soils. In the CLUB study unit, TDS was present at high concentrations in about $11 \%$ of the primary aquifer system and at moderate concentrations (between the recommended and upper limit) in 39\%.

Anoxic conditions (low amounts of dissolved oxygen) in groundwater may result in release of the naturally occurring elements manganese and iron from minerals into groundwater. Iron, or manganese, or both were present at high concentrations in about $3 \%$ of the primary aquifer system.

\section{Constituent of Special Interest: Perchlorate}

(Not included in water-quality overview charts shown on the front page)

Perchlorate is an inorganic constituent that has been regulated in California drinking water since 2007. It is an ingredient in rocket fuel, fireworks, safety flares and other products, may be present in some fertilizers, and also occurs at low concentrations under natural conditions in groundwater. Perchlorate was not detected at high concentrations, but was detected at moderate concentrations in about $32 \%$ of the primary aquifer system. 


\section{RESULTS: Groundwater Quality in the Borrego Valley, Central Desert, and Low-Use Basins of the Mojave and Sonoran Deserts Study Unit}

\section{ORGANIC CONSTITUENTS}

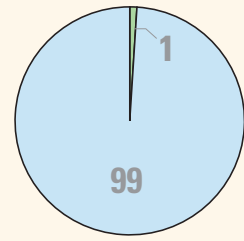

\section{Gasoline hydrocarbons}

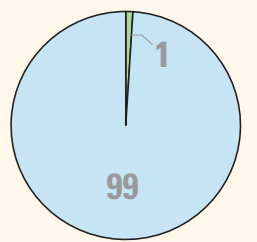

Solvents

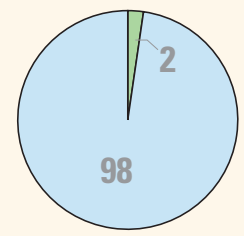

\section{Trihalomethanes}

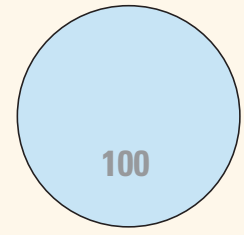

Other VOCs

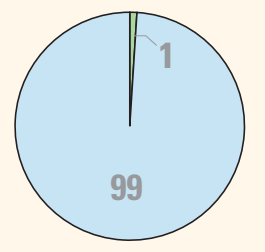

Herbicides and
insecticides
(including
fumigants)

\section{Organic Constituents}

The Priority Basin Project uses laboratory methods that can detect volatile organic compounds (VOCs) and pesticides at low concentrations far below human-health benchmarks. VOCs and pesticides detected at these low concentrations can be used to trace water from the landscape into the aquifer system.

\section{Volatile Organic Compounds with Human-Health Benchmarks}

VOCs are in many household, commercial, industrial, and agricultural products and are characterized by their tendency to volatilize (evaporate) into the air.

Gasoline hydrocarbons are a component of gasoline and may be used as additives to make gasoline burn more efficiently, improve emissions quality, and clean engine parts. In the CLUB study unit, gasoline hydrocarbons were not detected at high concentrations and were present at moderate concentrations in about $1 \%$ of the primary aquifer system.

Solvents are used for a number of purposes, including manufacturing and cleaning. Solvents were not detected at high concentrations and were present at moderate concentrations in about $1 \%$ of the primary aquifer system.

Trihalomethanes may form during disinfection of drinking-water supplies and may enter groundwater by the infiltration of landscape irrigation water or leakage from distribution systems. Trihalomethanes were not detected at high concentrations and were present at moderate concentrations in about $2 \%$ of the primary aquifer system.

Other volatile organic compounds, including organic synthesis reagents, were not detected at either high or moderate concentrations.

\section{Pesticides with Human-Health Benchmarks}

Pesticides, which include herbicides, fumigants, and insecticides, are applied to crops, gardens, lawns, around buildings, and along roads to help control unwanted vegetation (weeds), insects, fungi, and other pests. Insecticides were not detected at high concentrations in the primary aquifer system and were detected at moderate concentrations in about $1 \%$ of the primary aquifer system. Herbicides and fumigants were not detected at either high or moderate concentrations.

\section{BENCHMARKS FOR EVALUATING GROUNDWATER QUALITY}

GAMA's Priority Basin Project uses benchmarks established for drinking water to provide context for evaluating the quality of untreated groundwater. After withdrawal, groundwater may be disinfected, filtered, mixed, and exposed to the atmosphere before being delivered to consumers. Federal and California regulatory benchmarks for protecting human health (Maximum Contaminant Level, MCL) were used for the evaluation when available. Otherwise, non-regulatory benchmarks for protecting aesthetic properties, such as taste and odor (Secondary Maximum Contaminant Level, SMCL), and nonregulatory benchmarks for protecting human health (Notification Level, NL, and lifetime Health Advisory Level, HAL) were used.

\section{High, moderate, and low concentrations are defined relative to benchmarks}

Concentrations are considered high if they are greater than a benchmark. For inorganic constituents (except perchlorate), concentrations are moderate if they are greater than one-half of a benchmark. For organic and special-interest constituents (including perchlorate), concentrations are moderate if they are greater than one-tenth of a benchmark; this lower threshold was used because organic constituents generally are less prevalent and have smaller concentrations relative to benchmarks than inorganic constituents. Low includes nondetections and values less than moderate concentrations. Methods for evaluating water quality are discussed in Parsons and others (2014).

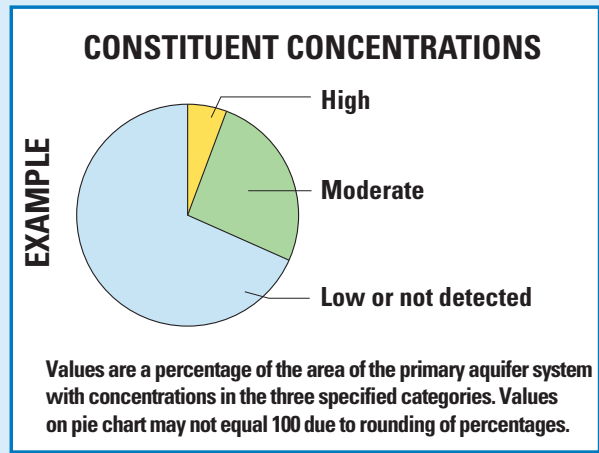

Values are a percentage of the area of the primary aquifer system
with concentrations in the three specified categories. Values on pie chart may not equal 100 due to rounding of percentages. 


\section{Trace and Minor Element Concentrations in the CLUB Study Unit}

In the CLUB study unit, trace and minor elements were present at high concentrations in $42 \%$ of the primary aquifer system. The proportion of the primary aquifer system having high concentrations was greatest in the Low-Use Basins study area (48\%) and lower in the Borrego Valley (29\%) and Central Desert (18\%) study areas. For comparison, the proportion of the primary aquifer system having high concentrations in the four other Mojave and Sonoran Desert areas ranged from 32\% to 40\% (Dawson and Belitz, 2012). The main contributors to high and moderate concentrations of trace and minor elements in the CLUB and other Mojave and Sonoran Desert study units were arsenic, boron, fluoride, molybdenum, and vanadium; however, different elements were important in different areas (Dawson and Belitz, 2012; Parsons and others, 2014). All five elements were present at high or moderate concentrations in the Low-Use Basins study area, whereas, three were present at high or moderate concentrations in the Borrego Valley study area (arsenic, fluoride, and vanadium), and three were present in the Central Desert study area (arsenic, fluoride, and molybdenum).

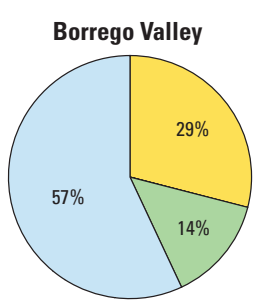

\section{Trace and minor elements}
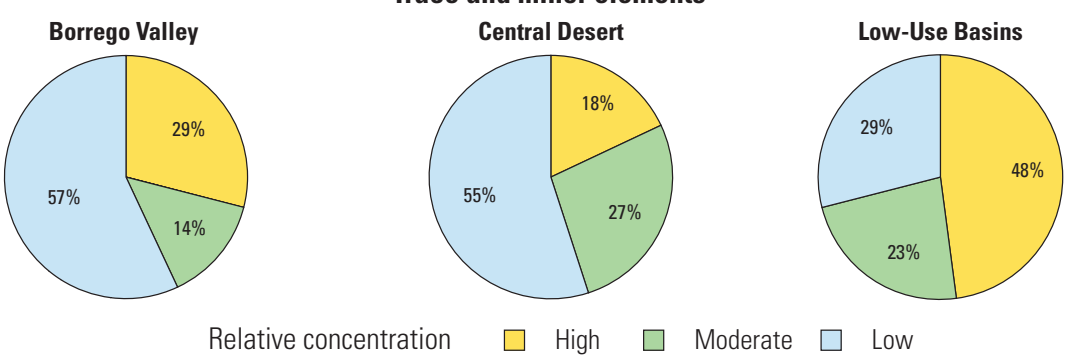

$\square$ High

$\square$ Moderate

$\square$ Low
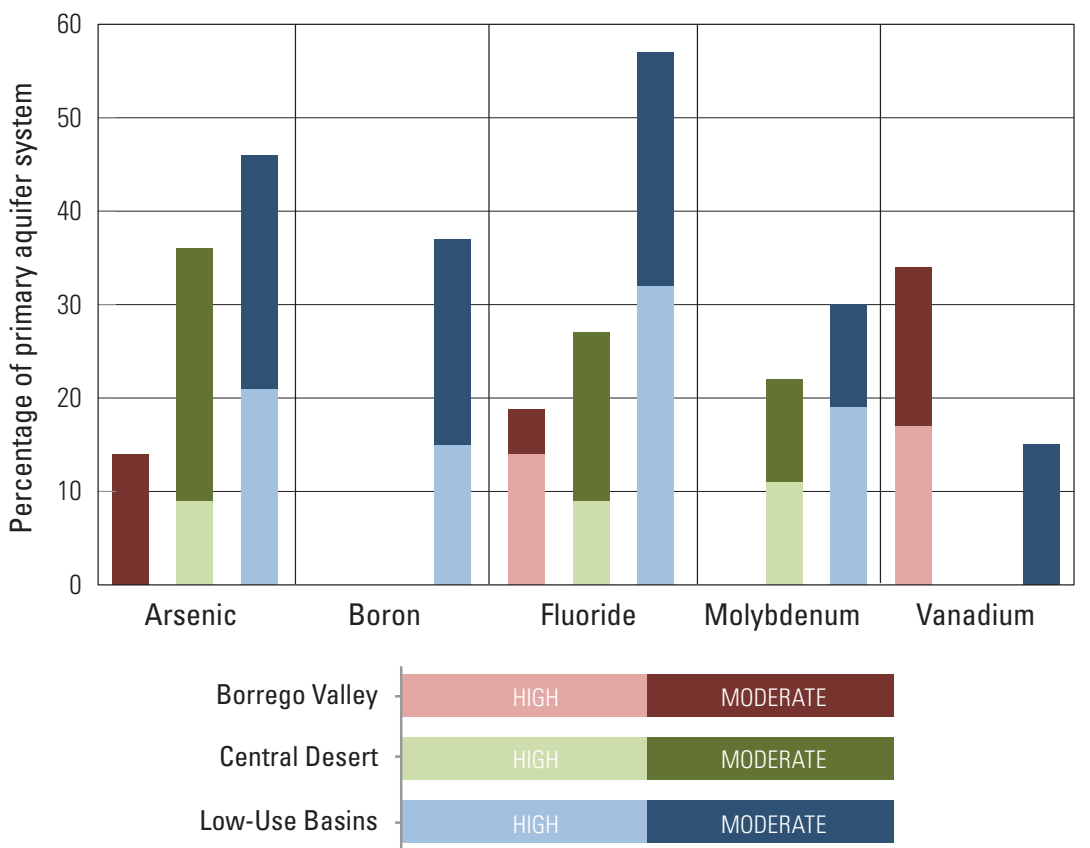

By Mary C. Parsons and Kenneth Belitz

\section{SELECTED REFERENCES}

California Department of Water Resources, 2003, California's groundwater: California Department of Water Resources Bulletin 118, 246 p. Available at http://www.water.ca.gov/groundwater/bulletin118/update2003. $c f m$.

Dawson, B.J.M., and Belitz, Kenneth, 2012, Status of groundwater quality in the California Desert Region, 2006-2008 - California GAMA Priority Basin Project: U.S. Geological Survey Scientific Investigations Report 2012-5040, 110 p. Available at http://pubs.usgs.gov/sir/2012/5040/.

Mathany, T.M., Wright, M.T., Beuttel, B.S., and Belitz, Kenneth, 2012, Groundwater-quality data in the Borrego Valley, Central Desert, and Low-Use Basins of the Mojave and Sonoran Deserts study unit, 2008-2010 - Results from the California GAMA Program: U.S. Geological Survey Data Series 659, 100 p. Available at http://pubs.usgs.gov/ds/659/.

Parsons, M.C., Hancock, T.C., Kulongoski, J.T., and Belitz, Kenneth, 2014, Status of groundwater quality in the Borrego Valley, Central Desert, and Low-Use Basins of the Mojave and Sonoran Deserts study unit, 2008-2010 - California GAMA Priority Basin Project: U.S. Geological Survey Scientific Investigations Report 2014-5001, 88 p. Available at http://pubs.usgs.gov/sir/2014/5001/.

\section{Priority Basin Assessments}

GAMA's Priority Basin Project (PBP) assesses water quality in that part of the aquifer system used for drinking water, primarily public supply. Water quality in shallower and deeper parts may differ from that in the primary aquifer system. GAMA's Domestic Well Project assesses water quality in the shallower parts of the aquifer system. Ongoing assessments are being conducted in more than 120 basins throughout California.

The PBP assessments are based on a comparison of constituent concentrations in untreated groundwater with benchmarks established for the protection of human health and for aesthetic concerns. The PBP does not evaluate the quality of drinking water delivered to consumers.

The PBP uses two scientific approaches for assessing groundwater quality. The first approach uses a network of wells to statistically assess the status of groundwater quality. The second approach combines water-quality, hydrologic, geographic, and other data to help assess the factors that affect water quality. In the Borrego Valley, Central Desert, and Low-Use Basins of the Mojave and Sonoran Deserts study unit, data were collected by the PBP from 2008 to 2010 and from the CDPH database for 2005-2008. The PBP includes chemical analyses not generally available as part of regulatory compliance monitoring, including measurements at concentrations much lower than human-health benchmarks and measurement of constituents that can be used to trace the sources and movement of groundwater.

\section{For more information}

Technical reports and hydrologic data collected for the GAMA Program may be obtained from

\section{GAMA Project Chief}

U.S. Geological Survey

California Water Science Center

6000 J Street, Placer Hall

Sacramento, CA 95819

Telephone number: (916) 278-3100

WEB: http://ca.water.usgs.gov/gama

\section{GAMA Program Unit Chief}

State Water Resources Control Board

Division of Water Quality

PO Box 2231, Sacramento, CA 95812

Telephone number: (916) 341-5779

WEB: http://www.waterboards.ca.gov/gama

ISSN 2327-6916 (print)

ISSN 2327-6932 (online)

http://dx.doi.org/10.3133/fs20143001 